\title{
Níveis de proteína bruta na dieta e desempenho reprodutivo de fêmeas primíparas em gestação
}

\author{
Kedson Raul de Souza Lima ${ }^{1}$, Aloízio Soares Ferreira ${ }^{2}$, Maria Cristina Manno ${ }^{3}$, Juarez Lopes \\ Donzele $^{2}$, Diogo Araujo 4
}

\footnotetext{
1 Universidade Federal Rural da Amazonia - Belém, PA.

2 Departamento de Zootecnia - UFV.

3 Zootecnista, M.S. Bioclimatologia Animal.

${ }^{4}$ Graduação em Agronomia - UFV. Bolsista PIBIC.
}

RESUMO - Foram testados três tratamentos $(10,0 ; 13,5$ e 17,0\% de PB) com o objetivo de avaliar o efeito dos níveis de proteína bruta na dieta sobre o desempenho eprodutivo de 36 fêmeas (12 por tratamento) suínas primíparas em gestação. As dietas continham (ou excediam) todos os nutrientes necessários para suprir as exigências dos animais, de acordo com o NRC (1998), à exceção dos níveis de proteína bruta. Embora a proteína tenha sido diluída com amido, a proporção aminoacídica foi mantida em todas as rações, em razão da relação constante nas quantidades de milho e farelo de soja. Foram avaliados o ganho de peso da fêmea durante a gestação, o número de leitões nascidos, o peso da leitegada, a espessura de toucinho e o desempenho da matriz durante a lactação e após o desmame. Não foram observadas diferenças significativas entre as médias das variáveis ganho de peso durante a gestação, espessura de toucinho, peso do leitão ao nascimento e número de leitões nascidos. Durante a lactação, não houve diferença entre os grupos de fêmeas alimentadas com níveis diferentes de proteína bruta na gestação para as variáveis consumo de ração, perda de peso, perda de espessura de toucinho, ganho diário de peso dos leitões e peso da leitegada ao desmame. Não houve efeito dos tratamentos no intervalo desmame-cio nos desempenhos reprodutivo e produtivo de fêmeas primíparas.

Palavras-chave: ganho de peso da fêmea, ingestão de alimento, nascidos vivos, peso do leitão ao nascimento

\section{Effects of feeding crude protein on the reproductive performance of females in the first pregnancy}

\begin{abstract}
Three treatments were accomplished (10.0, 13.5, and $17.0 \%$ of $\mathrm{CP})$ to evaluate the effect of dietary CP levels on the reproductive performance of 36 females (12 females per treatment) in the first pregnancy. The diets were formulated to contain (or to exceed) all the nutrients to meet the animal requirements, with the exception of $\mathrm{CP}$, according to NRC (1998). Although the protein was diluted with starch, the amino acid proportion was constant in all diet, due to the constant relation of the amounts of corn and soy meal. Gilt weight gain during the gestation, number of born pigs, litter weight, backfat thickness and nut performance during the nursing were evaluated. No significant differences among the averages of weight gain during the gestation, backfat thickness, piglet weight at birth and number of born piglets were observed. In the nursing phase, there was no effect of the groups of females fed different dietary CP levels in the gestation on feed intake, weight loss, backfat thickness loss, daily weight gain of the piglets and litter weight at weaning. No treatment effects on weaningestrus interval and reproductive and productive performances of females in the first pregnancy were observed.
\end{abstract}

Key Words: born alive, female weight gain, feed intake, piglet weight at birth

\section{Introdução}

Um dos maiores acontecimentos na produção de suínos nos últimos 30 anos foi o aumento da produtividade das matrizes, que passou de 16 para 22 leitões terminados/porca/ano. Esse acréscimo não foi proporcionado somente pelo aumento no número de leitões nascidos vivos, mas sim pelo maior conhecimento nas áreas de nutrição, saúde e manejo. O benefício maior foi o melhor conhecimento da fisiologia nutricional, que proporcionou a adoção de estratégias específicas para matrizes e marrãs (Close \& Cole, 2001).

Não ocorreram mudanças apenas no metabolismo das matrizes, mas também nos genótipos modernos, que se tornaram mais sensíveis à nutrição que seus predecessores, que possuíam mais reservas corporais no início da vida reprodutiva. Essa maior reserva propiciou a esses animais menores perdas quando em déficit nutricional. Esta situação 
tornou-se mais expressiva nas fêmeas suínas modernas, visto que a seleção para produção de tecido magro resultou em animais com baixa ingestão de alimento. Todos esses parâmetros foram observados por meio do conhecimento da fisiologia nutricional da fêmea suína nos últimos anos. Todavia, ainda existem muitas dúvidas sobre o metabolismo nutricional da fêmea, principalmente no tocante às exigências de energia e proteína nas fases de gestação e lactação.

A gestação é uma fase de necessidades especiais porque existe dupla demanda nutricional para o crescimento corporal e dos componentes da gestação (Balestra et al. 1998). Atualmente, as dietas para a fase de gestação apresentam de 12 a $13 \%$ de PB (NRC, 1998), com mesmo consumo durante toda a gestação, o que pode ser adequado para a nutrição de matrizes, mas parece inadequado para que marrãs gestantes expressem todo o seu potencial reprodutivo.

As exigências de aminoácido e proteína para a gestação são menores que para a lactação. Além disso, as matrizes, quando em condições de privação, são hábeis em proteger o desenvolvimento do feto utilizando o tecido maternal. Entretanto, o uso destes tecidos de reserva pode resultar em catabolismo severo durante a lactação, que pode aumentar o intervalo desmame-cobertura (King, 1987). O ganho de peso materno é a variável que responde melhor ao nível de proteína da dieta e, portanto, a dieta deveria se elaborada para promover ótimo crescimento e condição corporal a longo prazo, especialmente em marrãs.

Neste sentido, o estudo dos efeitos dos níveis de proteína na dieta de marrãs durante a gestação na formação dos fetos e no desempenho durante a lactação torna-se fundamental para o sucesso da produção suinícola. Como são poucas as pesquisas sobre o assunto, realizou-se este trabalho para avaliar os efeitos da proteína da ração de gestação sobre os desempenhos produtivo e reprodutivo de fêmeas suínas ao primeiro parto.

\section{Material e Métodos}

A pesquisa foi realizada no Setor de Suinocultura do Departamento de Zootecnia (DZO) da Universidade Federal de Viçosa no período de maio a novembro de 2001.

Foram utilizadas 36 fêmeas mestiças (Landrace x Large White) com média de $119,7 \mathrm{~kg}$, espessura de toucinho(ET) de 14,0 mm e 220 dias de idade, distribuídas em um delineamento em blocos inteiramente casualizados, com três tratamentos $(10,0 ; 13,5$ e 17,0\% de PB) de doze repetições. Adotou-se o peso corporal inicial das fêmeas como critério para bloqueamento.

As rações experimentais foram isoenergéticas, isovitamínicas e isominerálicas e suas composições são apresentadas na Tabela 1.
As rações experimentais foram obtidas a partir de rações formuladas de acordo com recomendações do NRC (1998), exceto quanto aos níveis de PB, que foram obtidos pela diluição da ração com nível mais elevado (17\%) com amido de milho, de forma a se manter uma relação constante entre milho e farelo de soja. Assim, foi possível manter constante a relação aminoacídica das três rações experimentais e, portanto, a mesma qualidade da proteína.

As marrãs foram alimentadas individualmente com 2,0 kg de ração/dia durante a gestação até os 110 dias de prenhez, quando passaram a receber quantidade equivalente a $3 \mathrm{~kg}$ de ração de lactação até o parto.

O fornecimento de ração na lactação iniciou-se na proporção de $1 \mathrm{~kg} / \mathrm{dia}$, aumentando gradativamente até atingir o máximo consumo, esperado para a primeira semana após o parto. Para maior eficiência no consumo, a ração foi dividida em três vezes por dia. As leitegadas foram equalizadas em número de 8 ou 9 leitões até três dias após o parto.

Para avaliação do efeito dos tratamentos na gestação e na fase de lactação, todas as matrizes receberam, durante a amamentação, a mesma dieta, cuja composição é descrita na Tabela 2. A ração para a fase de lactação foi formulada para conter $0,9 \%$ de lisina, excedendo a recomendação do NRC (1998), de 0,6\% de lisina.

Como o experimento foi realizado no inverno e no verão, foram medidas as variações climáticas durante o período (temperatura ambiente máxima e mínima, temperatura de bulbos úmido e seco e temperatura de globo negro) para explicar possíveis modificações no consumo de ração e no desempenho nas duas fases (gestação e principalmente lactação).

$\mathrm{O}$ aparecimento de cio nas marrãs foi observado no mínimo duas vezes ao dia utilizando-se um suíno macho adulto para assegurar a detecção do cio. As marrãs foram inseminadas no segundo cio. Após o desmame, a inseminação ocorreu no aparecimento do cio, sendo a observação iniciada três dias após o desmame. Quando ocorreram falhas na concepção, a fêmea foi novamente inseminada seguindo-se o ciclo normalmente. Somente foram descartados animais com problemas de saúde, locomoção, anestro e que retornaram ao cio mais de uma vez. O diluente utilizado na diluição do sêmen foi o Beltsville - TS (BTS) (Pusel \& Jonhston, 1975). Foram utilizados três machos $1 / 2$ irmãos para coleta de sêmen durante todo o período experimental.

As fêmeas foram alojadas individualmente em gaiolas de gestação onde ficaram até os 110 dias de gestação. Após este período, foram lavadas com água e sabão e encaminhadas para celas parideiras na maternidade, onde permaneceram 
Tabela 1 - Composição centesimal das rações experimentais Table 1 - Ingredient composition of the experimental diets

\begin{tabular}{|c|c|c|c|}
\hline \multirow[t]{2}{*}{$\begin{array}{l}\text { Ingrediente } \\
\text { Ingredient }\end{array}$} & \multicolumn{3}{|c|}{$\begin{array}{c}\text { Nível de proteína bruta (\%) } \\
\text { Crude protein level (\%) }\end{array}$} \\
\hline & 10,0 & 13,5 & 17,0 \\
\hline $\begin{array}{l}\text { Farelo de soja }(45 \% \mathrm{~PB}) \\
\text { Soybean meal }(45 \% \mathrm{CP})\end{array}$ & 14,20 & 19,42 & 24,63 \\
\hline $\begin{array}{l}\text { Milho }(8,5 \% \text { PB }) \\
\text { Corn }(8.5 \% \mathrm{CP})\end{array}$ & 39,70 & 54,30 & 68,77 \\
\hline $\begin{array}{l}\text { Amido } \\
\text { Starch }\end{array}$ & 37,95 & 19,44 & 1,00 \\
\hline $\begin{array}{l}\text { Óleo de soja } \\
\text { Soybean oil }\end{array}$ & 1,50 & 1,50 & 1,50 \\
\hline $\begin{array}{l}\text { Calcário } \\
\text { Limestone }\end{array}$ & 0,86 & 0,88 & 0,90 \\
\hline $\begin{array}{l}\text { Fosfato bicálcico } \\
\text { Dicalcium phosphate }\end{array}$ & 2,12 & 2,00 & 1,88 \\
\hline $\begin{array}{l}\text { Sal } \\
\text { Salt }\end{array}$ & 0,45 & 0,43 & 0,41 \\
\hline $\begin{array}{l}\text { Mistura mineral } \\
\text { Mineral mix }\end{array}$ & 0,05 & 0,05 & 0,05 \\
\hline $\begin{array}{l}\text { Mistura vitamínica }{ }^{2} \\
\text { Vitamin mix }\end{array}$ & 0,10 & 0,10 & 0,10 \\
\hline $\begin{array}{l}\text { Antioxidante } \\
\text { Antioxidant }\end{array}$ & 0,01 & 0,01 & 0,01 \\
\hline $\begin{array}{l}\text { Areia lavada } \\
\text { Washed sand }\end{array}$ & 3,06 & 1,87 & 0,66 \\
\hline Total $(\mathrm{kg})$ & 100,00 & 100,00 & 100,00 \\
\hline $\begin{array}{l}\text { Composição calculada } \\
\text { Calculated composition }\end{array}$ & & & \\
\hline $\begin{array}{l}\text { Proteína bruta }(\%) \\
\text { Crude protein }\end{array}$ & 10,00 & 13,50 & 17,00 \\
\hline $\begin{array}{l}\text { Cálcio (\%) } \\
\text { Calcium }\end{array}$ & 0,910 & 0,910 & 0,910 \\
\hline $\begin{array}{l}\text { Energia digestível }(\mathrm{kcal} / \mathrm{kg}) \\
\text { Digestible energy }\end{array}$ & 3.400 & 3.400 & 3.400 \\
\hline $\begin{array}{l}\text { Fibra bruta (\%) } \\
\text { Crude fiber }\end{array}$ & 1,615 & 2,209 & 2,802 \\
\hline $\begin{array}{l}\text { Fósforo total (\%) } \\
\text { Total phosphorus }\end{array}$ & 0,570 & 0,615 & 0,659 \\
\hline $\begin{array}{l}\text { Fósforo disponível (\%) } \\
\text { Available phosphorus }\end{array}$ & 0,450 & 0,450 & 0,450 \\
\hline $\begin{array}{l}\text { Lisina total }(\%) \\
\text { Lysine }\end{array}$ & 0,494 & 0,676 & 0,858 \\
\hline $\begin{array}{l}\text { Metionina }+ \\
\text { cistina total }(\%)\end{array}$ & 0,327 & 0,448 & 0,568 \\
\hline $\begin{array}{l}\text { Total methionine }+ \text { cystine } \\
\text { Sódio }(\%)\end{array}$ & 0,200 & 0,200 & 0,200 \\
\hline Sodium & & & \\
\hline $\begin{array}{l}\text { Treonina total }(\%) \\
\text { Total threonine }\end{array}$ & 0,384 & 0,525 & 0,666 \\
\hline $\begin{array}{l}\text { Triptofano total (\%) } \\
\text { Total tryptophan }\end{array}$ & 0,116 & 0,159 & 0,202 \\
\hline
\end{tabular}

1 Composição por kg de produto (Composition per $\mathrm{kg}$ of product): I - $1.500 \mathrm{mg}$; Co - 1.000 mg; Cu - 10.000 mg; Zn -10.000 mg; Mn - 40.000 mg;

2 Composição por $\mathrm{kg}$ de produto (Composition per $\mathrm{kg}$ of product): Vit. A 8.500.000 UI, Vit. $\mathrm{D}_{3}-1.300 .000$ UI, Vit. E $-20.000 \mathrm{mg}$, Vit. $\mathrm{K}_{3}-2.000$ $\mathrm{mg}$, Tiamina (Tiamin) - $2.000 \mathrm{mg}$, Riboflavina (Riboflavin) - $5.000 \mathrm{mg}$, Piridoxina (Piridoxin) - $1.600 \mathrm{mg}$, Vit. $\mathrm{B}_{12}-25.000 \mathrm{mcg}$, Niacina (Niacin) $40.000 \mathrm{mg}$, Pantotenato de cálcio (Calcium pantothenate) - $15.000 \mathrm{mg}$, Biotina (Biotin) - $120 \mathrm{mg}$, Se - $150 \mathrm{mg}$, BHT - $30.000 \mathrm{mg}$

até 21 dias (desmame) depois do parto. Não foi fornecida ração para os leitões no período de aleitamento.

As fêmeas gestantes foram pesadas no período de cobertura e aos 30, 60, 90 e 110 dias de gestação, enquanto
Tabela 2 - Composição centesimal da ração de lactação Table 2 - Ingredient composition of the lactating diet

\begin{tabular}{lr}
$\begin{array}{l}\text { Ingrediente } \\
\text { Ingredient }\end{array}$ & $\begin{array}{c}\text { Quantidade } \\
\text { Amount }\end{array}$ \\
\hline Farelo de soja (45\% PB) (Soybean meal) & 23,30 \\
Milho (8,5\% PB) (Corn) & 70,78 \\
Óleo de soja (Soybean oil) & 2,00 \\
Calcário (Limestone) & 0,82 \\
Fosfato bicálcico (Dicalcium phosphate) & 2,40 \\
Sal (Salt) & 0,50 \\
Suplemento mineral ${ }^{1}$ (Mineral mix) & 0,05 \\
Suplemento vitamínico $^{2}$ (Vitamin mix) & 0,10 \\
Cloreto de colina (Choline chloride) $_{\text {Antioxidante (Antioxidant) }}$ & 0,04 \\
Total (kg) & 0,01 \\
\end{tabular}

Composição calculada

Calculated composition

Proteína bruta (\%) (Crude protein) 17,64

Cálcio (\%) (Calcium) 0,97

Energia digestível ( $\mathrm{kcal} / \mathrm{kg})$ (Digestible energy) 3.450

Fibra bruta (\%) (Crude fiber) 2,88

Fósforo total (\%) (Total phosphorus) 0,65

Fósforo disponível (\%) (Available phosphorus) 0,43

Lisina (\%) (Lysine) $\quad 0,90$

Metionina + cistina (\%) (Methionine + cystine) 0,56

Sódio (\%) (Sodium) 0,22

Treonina (\%) (Threonine) 0,69

Triptofano (\%) (Tryptophan) 0,21

${ }^{1}$ Composição por kg de produto (Composition per kg of product): I - $1.500 \mathrm{mg}$ Co $-1.000 \mathrm{mg}, \mathrm{Cu}-10.000 \mathrm{mg}, \mathrm{Zn}-10.000 \mathrm{mg}, \mathrm{Mn}-40.000 \mathrm{mg}$.

2 Composição por $\mathrm{kg}$ de produto (Composition per $\mathrm{kg}$ of product): Vit. A 8.500 .000 UI, Vit. $D_{3}-1.300 .000$ UI, Vit. E - $20.000 \mathrm{mg}$, Vit. $K_{3}-2.000 \mathrm{mg}$, Tiamina (Tiamin) - $2.000 \mathrm{mg}$, Riboflavina (Riboflavin) $-5.000 \mathrm{mg}$, Piridoxina (Piridoxin) - $1.600 \mathrm{mg}$, Vit. B $12-25.000 \mathrm{mcg}$, Niacina (Niacin) $-40.000 \mathrm{mg}$ Pantotenato de cálcio (Calcium pantotenate) - $15.000 \mathrm{mg}$, Biotina (Biotin) $120 \mathrm{mg}$, Se - $150 \mathrm{mg}$, Antioxidante (Antioxidant) - $30.000 \mathrm{mg}$.

as porcas lactantes e as leitegadas foram pesadas 24 horas após o parto e aos 7, 14 e 21 dias. O ganho de peso da fêmea durante a gestação, descontando a leitegada e os resíduos do parto, foi obtido pela diferença entre o peso após o parto e o peso à cobertura. Na primeira pesagem após o parto (24 horas), foram realizadas as marcações e o corte dos dentes e da cauda dos leitões. A espessura de toucinho foi medida na cobertura, no parto e ao desmame. Para determinação do ganho ou da perda de toucinho no intervalo do desmame à próxima inseminação, foi realizada a medição da espessura de toucinho no desmame e logo após a inseminação. Estas medidas foram feitas a $6,5 \mathrm{~cm}$ da coluna vertebral, entre a penúltima e última costela (ponto $\mathrm{P} 2$ ), utilizando-se instrumento de ultra-som desenvolvido pela EMBRAPA.

Durante o período do desmame à cobertura, as fêmeas foram alojadas em piquetes de terra para recuperar possíveis lesões nos cascos e receberam ração de lactação na quantidade de até $3,0 \mathrm{~kg}$ por dia.

O desempenho da fêmea foi avaliado pelos seguintes parâmetros produtivos: peso do leitão ao nascimento, número total de nascidos, nativivos, natimortos, mumifica- 
dos, peso da leitegada e do leitão ao desmame, ganho de peso diário do leitão, número de leitões desmamados, ganho de peso da fêmea durante a gestação, ganho em espessura de toucinho no ponto $\mathrm{P} 2$, consumo de ração pela fêmea na lactação, perda de peso e espessura de toucinho na lactação e dias para retorno ao cio após o desmame.

O ganho de peso da fêmea na gestação foi avaliado pela covariável peso à cobertura; o peso do leitão ao nascimento, pela covariável número de nascidos totais; a variação do peso na lactação, pela covariável consumo na lactação; e a variação na espessura de toucinho, pela covariável espessura de toucinho no parto. Como durante a lactação ocorrem perdas e os números se tornam negativos (dificulta análise estatística em razão da grande variação), foi necessário transformar os números relacionados às perdas em porcentagem, ou seja, em valores relativos, que foram chamados mudanças no peso corporal ou na espessura de toucinho.

Aplicou-se o teste SNK para testar contrastes entre as médias dos tratamentos nos parâmetros avaliados. A análise estatística das variáveis testadas foi realizada utilizando-se o programa computacional SAS (2001), de acordo com o seguinte modelo estatístico:

$$
Y i j=m+t i+b j+e i j,
$$

em que Yij = valor observado na parcela relativa ao tratamento (nível de PB) i no bloco (peso) j; m = média geral; $\mathrm{ti}=$ efeito atribuído ao nível de $\mathrm{PB} ; \mathrm{bj}=$ efeito relativo ao peso; eij = efeito dos fatores não-controlados (erro experimental).

\section{Resultados e Discussão}

Os resultados de ganho de peso e espessura de toucinho das fêmeas durante a gestação são apresentados na Tabela 3.

Não houve diferença significativa entre os tratamentos $(\mathrm{P}>0,10)$ para o ganho de peso (GP) da cobertura aos 30 dias, dos 30 aos 60 dias, dos 60 aos 90 dias e dos 90 aos 110 dias de gestação. Entretanto, em valores absolutos, houve aumento no ganho à medida que se elevou o nível de $\mathrm{PB}$ da ração. Estes valores talvez não tenham sido significativos, em virtude do elevado valor do coeficiente de variação obtido com as respectivas variáveis, mesmo considerando aceitável o coeficiente de variação de $35 \%$ para ganho de peso de reprodutoras (Judice et al., 1999). Embora com coeficiente não-significativo, os dados corroboram os obtidos por Close \& Cole (2001), visto que o aumento da ingestão de proteína propiciou a elevação no ganho de peso das matrizes.

A diferença de médias em GP da cobertura ao parto entre os tratamentos foi significativa $(\mathrm{P}<0,05)$ pelo teste SNK. As matrizes que ingeriram maior quantidade de proteína obtiveram maior GP. No entanto, embora não-significativo ( $\mathrm{P}>0,10)$, o valor absoluto de GET foi superior nas fêmeas que ingeriram maior quantidade de $\mathrm{PB}(10 \%)$, indicando que o aumento de peso, durante a gestação, nessas matrizes pode ter ocorrido mais em forma de tecido muscular que de tecido gorduroso. Mahan (1998), trabalhando com dois níveis de proteína ( 13 vs $16 \%$ ) e dois níveis de alimentação (1,8 e 1,9+0,096 a cada parto sucessivo) em cinco partos consecutivos, verificou menor espessura de toucinho (ET)

Tabela 3 - Peso à cobertura (PC), espessura de toucinho à cobertura (ETC) e ganhos de peso (GP) e de espessura de toucinho (GET) de fêmeas suínas submetidas a diferentes níveis de PB durante a gestação

Table 3 - Values of the mating weight (MW), backfat thickness in the mating (BTM), weight gain (WG) and backfat thickness (BT) of gilts fed different dietary $\mathrm{CP}$ levels in the gestation

\begin{tabular}{|c|c|c|c|c|c|}
\hline \multirow[t]{2}{*}{$\begin{array}{l}\text { Variável } \\
\text { Variable }\end{array}$} & \multicolumn{3}{|c|}{$\begin{array}{c}\text { Nível de PB }(\%) \\
\text { CP level }\end{array}$} & \multirow[t]{2}{*}{$\mathrm{P}$} & \multirow[t]{2}{*}{$\mathrm{CV}$} \\
\hline & 10,0 & 13,5 & 17,0 & & \\
\hline Fêmea total (Total female) & 12,0 & 12,0 & 12,0 & & \\
\hline $\mathrm{PC}, \mathrm{kg}(M W)$ & 119,7 & 119,6 & 119,9 & & \\
\hline $\operatorname{ETC}(\mathrm{mm})(G B T)$ & 14,5 & 14,8 & 14,6 & & \\
\hline \multicolumn{6}{|l|}{ GP $\quad(\mathrm{kg})(G W)$} \\
\hline 0 a 30 dias (0 to 30 days) & 11,84 & 13,50 & 14,58 & NS & 35,1 \\
\hline 30 a 60 dias (30 to 60 days) & 15,17 & 16,58 & 18,67 & NS & 34,4 \\
\hline 60 a 90 dias (60 to 90 days) & 12,91 & 13,25 & 15,25 & NS & 30,9 \\
\hline 90 a 110 dias (90 to 110 days) & 11,67 & 12,75 & 13,92 & NS & 37,4 \\
\hline 0 a 110 dias (0 to 110 days) & 51,58 & 56,08 & 61,42 & NS & 21,4 \\
\hline 0 ao parto $^{1}$ (at forrowing) & $39,88 \mathrm{~b}$ & $46,84 \mathrm{a}$ & $51,17 \mathrm{a}$ & 0,04 & 14,8 \\
\hline $\operatorname{GET}(\mathrm{mm})(B T G)$ & 3,83 & 2,41 & 3,34 & NS & 68,4 \\
\hline
\end{tabular}

NS - Não-significativo ( $P>0,10)$ (Not significant).

1 Letras diferentes na mesma linha diferem entre as médias pelo teste SNK

${ }^{1}$ Means followed by different letters in the same row differ by test SNK. 
no parto, no desmame e na cobertura no grupo de matrizes que recebeu maior nível protéico.

Os maiores ganhos ocorreram nos primeiros 60 dias da gestação, justamente no período em que se acredita haver "sobra" de nutrientes para a fêmea em razão da menor demanda para o desenvolvimento fetal. Este ganho pode ter sido maior pelo fato de as fêmeas serem primíparas e não terem atingido o peso adulto, depositando ainda tecido de reserva. Tem-se verificado que a fêmea neste período constrói ou repõe parte de seus tecidos de reservas (proteína e gordura) (Cole, 1990) e que é no segundo terço da gestação que ocorrem maior crescimento de tecido maternal e aumento das células musculares no feto (hiperplasia) (Maxwell \& Sohn, 1999). Não se tem verificado efeito dos níveis de ingestão de proteína sobre o desenvolvimento das fibras musculares no feto, mas tem-se observado que o menor número destas células pode prejudicar o desempenho dos leitões após o desmame, pois após o nascimento não há formação, apenas crescimento (hipertrofia) das fibras musculares (Close \& Cole, 2001).

Os resultados de desempenho das leitegadas e das fêmeas são apresentados nas Tabelas 4 e 5 . O número de leitões nascidos totais e nascidos vivos não diferiu estatisticamente entre tratamentos $(\mathrm{P}>0,10)$, assim como as médias do peso dos leitões ao nascimento. Apesar de não ter diferido estatisticamente $(\mathrm{P}>0,10)$, o peso ao nascimento dos leitões das fêmeas do tratamento com $17,0 \%$ de PB foi, em valor absoluto, maior que o observado nos tratamentos com $13,5 \%$ e com $10,0 \%$ PB. Todavia, em todos os tratamentos o peso médio do leitão ao nascimento foi superior a $1,3 \mathrm{~kg}$, considerado adequado por Cromwell (2001).

A ingestão de proteína não afeta o tamanho da leitegada, mas pode afetar o peso dos leitões ao nascimento. Shields et al. (1985), trabalhando com dois níveis de PB (5 e 14\%) durante a fase de gestação, verificaram redução no peso do leitão ao nascimento para o menor nível de proteína. Todavia, Mahan (1998) testou dois níveis de PB (13 e 16\%) durante cinco partos sucessivos e não notou redução do peso da leitegada ao nascimento para o maior nível protéico.

Shields et al. (1985) observaram que, quando há modificação no peso do leitão ao nascimento, geralmente a qualidade da proteína é inadequada (relação lisina x demais aminoácidos), o que não depende da quantidade de proteína.

Tem-se constatado relação inversa entre o número de leitões nascidos e o peso do leitão ao nascimento. No entanto, não foi verificado valor significativo $(\mathrm{P}>0,10)$ do peso do leitão ao nascimento para número menor de leitões nascidos, o que diverge dos relatos de Cromwell (2001) que analisou dados de várias leitegadas em uma série de 15 anos e verificou que, para cada leitão nascido a mais na leitegada, a média de peso de leitões nascidos decresceu $40 \mathrm{~g}$.

Embora não-significativo estatisticamente, o menor peso do leitão ao nascimento persistiu por todo o período de lactação, a cada intervalo de semana (7, 14 e 21 dias), o que confirma a afirmativa de Cromwell (2001) de que leitões mais pesados ao nascimento apresentam maior peso à desmama e vice-versa. Esse menor peso pode ter influenciado

Tabela 4 - Características das leitegadas do nascimento ao desmame de matrizes submetidas a diferentes níveis de PB na ração durante a gestação

Table 4 - Characteristics of litters from birth to weaning of sows fed different dietary CP levels in the gestation

\begin{tabular}{|c|c|c|c|c|c|}
\hline \multirow[t]{2}{*}{$\begin{array}{l}\text { Variável } \\
\text { Variable }\end{array}$} & \multicolumn{3}{|c|}{$\begin{array}{c}\text { Nível de PB (\%) } \\
\text { CP level }\end{array}$} & \multirow[t]{2}{*}{$\mathrm{P}$} & \multirow[t]{2}{*}{$\mathrm{CV}$} \\
\hline & 10,0 & 13,5 & 17,0 & & \\
\hline Nascidos totais (Born total) & 9,9 & 10,9 & 10,2 & NS & 23,6 \\
\hline Nascidos vivos (Born alive) & 9,0 & 9,9 & 8,7 & NS & 25,2 \\
\hline Mumificados & 0,2 & 0,1 & 0,5 & NS & 214,2 \\
\hline Natimortos (Stillborn) & 0,7 & 0,9 & 1,0 & NS & 124,5 \\
\hline Peso da leitegada ao nascimento, $\mathrm{kg}$ (Littter weight at birth) & 13,30 & 13,64 & 13,81 & NS & 22,3 \\
\hline Peso da leitegada ao desmame, $\mathrm{kg}$ (Littter weight at weaning) & 47,66 & 44,43 & 47,57 & NS & 19,8 \\
\hline \multicolumn{6}{|l|}{ Peso leitão, $\mathrm{kg}$ (Piglet weight) } \\
\hline Ao nascimento (At birth) & 1,48 & 1,38 & 1,59 & NS & 20,1 \\
\hline Aos $7 \operatorname{dias}^{1}$ (At 7 days) & $2,63 \mathrm{ab}$ & $2,34 b$ & $2,92 \mathrm{a}$ & 0,04 & 14,9 \\
\hline Aos 14 dias (At 14 days) & 4,06 & 3,67 & 4,06 & NS & 12,8 \\
\hline Aos 21 dias (At 21 days) & 5,43 & 5,06 & 5,4 & NS & 14,1 \\
\hline $\mathrm{N}^{0}$ de leitões aos 21 dias ( $N$. of piglet at 21 days) & 8,8 & 8,8 & 8,7 & - & - \\
\hline Ganho diário do leitão, g (Daily weight gain) & 187,3 & 174,3 & 185,0 & NS & 19,6 \\
\hline
\end{tabular}

NS - Não-significativo ( $P>0,10)$ (Not significant).

${ }^{1}$ Médias com letras distintas na mesma linha diferem estatisticamente pelo teste SNK.

${ }^{1}$ Means followed by different letters in the same row differ by test SNK. 
Tabela 5 - Desempenho na lactação de fêmeas de primeiro ciclo submetidas a diferentes níveis de proteína na ração durante a gestação Table 5 - Performance in the lactation of sows of first cycle submitted at different protein levels in the gestation

\begin{tabular}{|c|c|c|c|c|c|}
\hline \multirow[t]{2}{*}{$\begin{array}{l}\text { Variável } \\
\text { Variable }\end{array}$} & \multicolumn{3}{|c|}{$\begin{array}{l}\text { Níveis de } \mathrm{PB}(\%) \\
\text { Crude protein level }\end{array}$} & \multirow[t]{2}{*}{$\mathrm{P}$} & \multirow[t]{2}{*}{$\mathrm{CV}$} \\
\hline & 10,0 & 13,5 & 17,0 & & \\
\hline \multicolumn{6}{|l|}{ Peso da fêmea, $\mathrm{kg}$ (Sow weight) } \\
\hline Parto (Parity) & 159,58 & 166,42 & 170,84 & & \\
\hline Desmame (Weaning) & 154,75 & 159,84 & 166,25 & & \\
\hline Perda de peso $21 \mathrm{~d}, \mathrm{~kg}$ (Weight loss at 21 days) & 1,85 & 6,55 & 4,58 & NS & - \\
\hline \multicolumn{6}{|l|}{$\mathrm{ET}, \mathrm{mm}(B T)$} \\
\hline Parto (Parity) & 16,0 & 17,4 & 17,5 & NS & - \\
\hline Desmame (Weaning) & 14,4 & 15,1 & 15,1 & NS & - \\
\hline Perda ET parto/desmame (Parity BT lost/weaning) & 1,6 & 2,3 & 2,4 & NS & - \\
\hline $2^{\mathrm{a}}$ cobertura $\left(2^{\text {th }}\right.$ mating $)$ & 14,4 & 13,8 & 13,8 & NS & - \\
\hline Perda desmame $/ 2^{\mathrm{a}}$ cobertura (Lost weaning $/ 2^{\text {nd }}$ mating) & 0,0 & 1,3 & 1,3 & NS & - \\
\hline \multicolumn{6}{|l|}{ Peso relativo, $\%^{1}$ (Relative weight) } \\
\hline 21 dia (21 days) & 98,8 & 96,3 & 97,3 & NS & 4,9 \\
\hline \multicolumn{6}{|l|}{ Mudança na ET, \% ${ }^{2}$ (BT change, \%) } \\
\hline Parto/desmame (Parturition/weaning) & 91,2 & 86,9 & 88,3 & NS & 13,2 \\
\hline Desmame $/ 2^{\mathrm{a}}$ cobertura (Weaning $/ 2^{\text {nd }}$ mating) & 100,0 & 93,4 & 92,3 & NS & 15,5 \\
\hline Consumo ração, $\mathrm{kg}$ (Feed intake) & 4,36 & 4,07 & 4,34 & NS & 12,1 \\
\hline $\mathrm{IDC}^{3}$, dias $(W E D$, days $)$ & 6,8 & 6,4 & 6,1 & NS & 19,6 \\
\hline Ganho líquido, kg (Net gain) & 32,1 & 29,7 & 28,1 & NS & 23,1 \\
\hline
\end{tabular}

${ }_{1}$ Peso relativo (Peso final ${ }^{*} 100 /$ Peso inicial) (Relative weight [Final weight ${ }^{*} 100 /$ Initial weight]).

2 Mudança relativa (ET final*100/ET inicial) (Relative change [Final BT *100/initial BT]).

3 Intervalo desmame-cio (Weaning-estrus days).

NS - não-significativo $(P>0,10)$ (Not significant).

também o ganho diário de peso (GDP) dos leitões das fêmeas alimentadas com rações contendo $13,5 \%$ de PB, embora não tenha havido diferença significativa $(\mathrm{P}>0,10)$ nas médias de GDP entre os tratamentos. Apesar de não ter sido verificado o nível de infestação e o tipo de agente patogênico, constatou-se presença de diarréia em todas as leitegadas, o que talvez possa explicar o baixo desempenho, considerando-se que leitões acometidos por diarréia podem deixar de ganhar até $0,45 \mathrm{~kg}$ durante a lactação (Moraes, 1993). Os valores de ganho diário obtidos neste estudo foram inferiores ao considerado ideal (250 g/dia) (Close \& Cole, 2001).

Não houve diferença significativa $(\mathrm{P}>0,10)$ entre as médias das variáveis obtidas nas matrizes durante a lactação em função dos tratamentos. A fêmea lactante parece não ser hábil em produzir leite sem perder peso. A perda de peso durante a lactação é aceitável desde que não ultrapasse $10,0 \mathrm{~kg}$ (Close \& Cole, 2001). Em nenhum dos tratamentos foi observada perda de peso superior a 7,0 kg. Por serem matrizes de primeiro parto, provavelmente sejam susceptíveis à maior perda de peso decorrente do baixo consumo de alimento, da pequena quantidade de tecidos de reserva, entre outras causas. Close \& Cole (2001) citaram que o ideal durante o período de lactação seria a fêmea não perder mais que $3 \mathrm{~mm}$ de espessura de toucinho no ponto P2, pois maiores perdas de peso e de espessura de toucinho poderiam elevar o intervalo desmame-cio (IDC), o que, possivel- mente, impossibilitou a detecção de diferenças estatísticas significativas $(\mathrm{P}>0,10)$ para IDC nas matrizes deste estudo. Geralmente, o primeiro sintoma quando a fêmea apresenta balanço energético negativo é o aumento no IDC (Close \& Cole, 2001).

A inabilidade da fêmea lactante em manter a produção de leite sem perder peso talvez possa ser explicada pela seleção genética, que foi voltada para a produção de tecido magro, o que impossibilita a deposição de maiores quantidades de gordura. A relação gordura:proteína do leite nessa espécie é alta (Ferreira et al., 1988) e, para que haja fluxo contínuo e crescente de leite durante o período de lactação, a fêmea necessita receber energia da dieta. Quando não há esta oferta de nutriente, a fêmea utiliza suas reservas e, conseqüentemente, perde peso. Mesmo menor que a energia, a quantidade de proteína no leite também é alta (Ferreira et al., 1988) e, quando escassa, normalmente ocorre o mesmo processo descrito anteriormente. Durante a lactação pode-se verificar perda tanto de gordura quanto de proteína e, dependendo do nível, estas perdas podem elevar o período desmame-cobertura ou diminuir a produção de leitões no parto subseqüente (Close \& Cole, 2001).

Embora o consumo médio de ração entre os animais dos diversos tratamentos não tenha apresentado diferença significativa ( $\mathrm{P}>0,10)$, observou-se consumo de ração 290 e 270 g menor no tratamento $13,5 \%$ de $\mathrm{PB}$ em relação ao dos tratamentos 10,0 e $17,0 \%$ de $\mathrm{PB}$, respectivamente, aos 21 
dias de lactação. Também houve maior perda de espessura de toucinho nas matrizes dos tratamentos $2(13,5 \%$ de PB) e $3(17 \%$ de $\mathrm{PB})$. A redução na espessura de toucinho atribuída à diminuição no consumo de alimento durante a lactação (ingestão de energia) também foi observada por Mullan (1991). Normalmente, matrizes perdem toucinho durante a lactação, mas, se há aumento na ingestão de energia, essas perdas decrescem (Close \& Cole, 2001).

Não houve diferença significativa $(\mathrm{P}>0,10)$ entre as médias para a ET nos períodos parto-desmame e desmamecobertura. A maior perda de toucinho no ponto P2 foi observada no tratamento com maior nível protéico (17\% de PB), seguido do tratamento $13,5 \%$ de PB. No entanto, o IDC foi menor para as fêmeas submetidas a estes dois tratamentos. Maior perda de toucinho durante a lactação aumenta o intervalo desmame-cobertura (Close \& Cole, 2001). Whittemore \& Morgan (1990), ao estimarem a quantidade de gordura em matrizes, considerando a espessura de toucinho no ponto $\mathrm{P} 2$ e o peso corporal, também observaram este fenômeno. Esta variação na espessura de toucinho também foi verificada, neste estudo, no período desmamecobertura nos animais submetidos a diferentes níveis de energia e proteína na ração.

Durante o período desmame-cobertura, as fêmeas perderam peso, possivelmente pelo fato de a alimentação ter sido controlada durante esta fase $(3,0 \mathrm{~kg}$ de ração de lactação) ou porque os animais foram mantidos em piquetes de terra para recuperação de escoriações nos cascos. Neste período, são comuns recomendações para se aumentar o fornecimento de alimento para recuperação do tecido perdido na fase de lactação. Estratégia ideal, segundo Roppa (2001), seria alimentar as fêmeas ad libitum com uma ração de padrão nutricional intermediário entre o da gestação e o da lactação.

O ganho de peso líquido das fêmeas da primeira até a segunda cobertura não foi estatisticamente significativo $(\mathrm{P}>0,10)$, indicando que o nível de proteína talvez não prejudique o desempenho subseqüente.

\section{Conclusões}

O nível de $\mathrm{PB}$ da ração de gestação não afetou os desempenhos reprodutivo e produtivo de fêmeas suínas primíparas.

\section{Literatura Citada}

BALESTRA, B.A.; RICHERT, B.T.; FRANK, J.W. Effect of gestation dietary crude protein level on the gestation and lactation performance of primiparous sows. Swine Day Report, Purdue University. 1998.

CLOSE, W.H.; COLE, D.J.A. Nutrition of sows and boars. British Library cataloguing in publication data. Nottingham: Nottingham University Press, 2001. 378p.

COLE, D.J.A. Nutritional strategies to optimize reproduction in pigs. Journal of Reproduction and Fertility, v.40, p.65-67, 1990 (Suppl.).

CROMWELL G.G. Biologic relationships of birth and weaning traits in pigs. The Farmer's Pride, KPPA News, v.12, n.47, p.1-8, 2001.

FERREIRA, A.S.; COSTA, P.M.A.; ANNA; R.S. et al. Composição de leite de porca. Revista da Sociedade Brasileira de Zootecnia, v.17, n.3, p.212-220, 1988.

JUDICE, M.G.; MUNIZ, J.A.; CARVALHEIRO, R. Avaliação do coeficiente de variação em experimentação com suínos. Ciência e Agrotecnologia, v.23, n.1, p.170-173. 1999.

KING, R.H. Nutritional anoestrus in growing sows. Pig News and Information, v.8, p.15-22. 1987.

MAHAN, D.C. Relationship of gestation protein and feed intake level over a five-parity period using a high-producing sow genotype. Journal of Animal Science, v.76, n.2, p.533-541, 1998.

MAXWELL, C.V.; SOHN, K. S. The pros and cons of SEW system - Review. Asian Australasian Journal Animal Science, v.12, n.2, p.226-232, 1999.

MORAES, N. Fatores que limitam a produção de leitões na maternidade. Suinocultura Dinâmica. Periódico técnico informativo - EMBRAPA-CNPSA, Ano II, n.9, 1993. 6p.

MULLAN, B.P. The catabolism of fat and lean by sows during lactation. Pig News and Information, v.12, p.221-225, 1991.

NATIONAL RESEARCH COUNCIL - NRC. Nutrient requirements of swine. 9.ed.rev. \{S.I\}: National Academy Press, 1998. 188p.

PUSEL, V.G.; JONHSTON, L.A. Freezing of board spermatozoa:fertilizing capacity with concentrated semen and a new thawing procedure. Journal of Animal Science, v. 40 , n.3, p.99-102, 1975

ROPPA, L. Manejo e nutrição da fêmea suína. 2001. Disponível em: www.porkworld.com.br. Acesso em: 12/04/2001.

STATISTICAL ANALYSES SYSTEM - SAS. SAS Linguage reference. Version 8, Cary: 2001. 1042p.

SHIELDS JR., R.G.; MAHAN, D.C.; MAXON, P.F. Effect of dietary gestation and lactation protein level on reproductive performance and body composition of first-litter female swine. Journal of Animal Science, v.60, p.179-189, 1985.

WHITTEMORE, C.T.; MORGAN, C.A. Model components for the determination of energy and protein requirements for breeding sows: a review. Livestock Production Science, v.26, p.1-37, 1990 . 